\title{
Extramedullary Hematopoiesis
}

National Cancer Institute

\section{Source}

National Cancer Institute. Extramedullary Hematopoiesis. NCI Thesaurus. Code C41235.

Hematopoiesis that occurs outside of the bone marrow. It occurs during fetal

development or it may result from pathologic processes that affect the bone marrow. 